\title{
Evaluation of urinary NGAL level in children with congenital heart disease as a possible early indicator of nephropathy
}

\author{
Hossein Emad Momtaz ${ }^{1^{*}}$, Asadolah Tanasan $^{2^{\circledR}}$, Majid Godini $^{3}$ \\ ${ }^{1}$ Division of Pediatric Nephrology, Hamadan University of Medical Sciences, Besat Hospital, Hamadan, Iran \\ ${ }^{2}$ Division of Pediatric Cardiology, Hamadan University of Medical Sciences, Besat Hospital, Hamadan, Iran \\ ${ }^{3}$ Faculty of Medicine, Hamadan University of Medical Sciences, Besat Hospital, Hamadan, Iran
}

\section{A R T I C L E I N F O}

\section{Article Type:}

Original

\section{Article History:}

Received: 11 April 2020

Accepted: 7 June 2020

Published online: 14 September 2020

Keywords:

NGAL

Nephropathy

Congenital heart disease

Children

\begin{abstract}
A B S T R A C T
Introduction: Nephropathy as a consequence of congenital heart disease (CHD), especially cyanotic heart disease, has been detected since past decades. However, lack of a diagnostic method at early stages of the disease, caused patients referring when nephropathy is established and also complicated with severe proteinuria and renal failure. Urinary neutrophil gelatinase-associated lipocalin (NGAL) is known as one of the newest biomarkers for early detection of renal parenchymal damage. In this study, we attempted to evaluate the role of urinary NGAL level in early detection of nephropathy in pediatrics with CHD.

Objectives: The aim of this study was to evaluate urinary NGAL as a potential biomarker for the early detection of renal involvement in children with CHD.

Patients and Methods: In this case-control study, urinary NGAL levels of 42 children with CHD (case group) and 42 healthy children (control group) with the matched ages were measured. Afterward, we compared mean urinary NGAL levels between these two groups to find a possible significant difference.

Results: In this study, mean urinary NGAL level in patients with CHD and healthy children was $3.83 \mu \mathrm{g} / \mathrm{mL}$ and $1.87 \mu \mathrm{g} / \mathrm{mL}$, respectively. Although the mean urine NGAL level was higher in children with CHD compared to healthy children, this difference was not statistically significant. Conclusion: in this study, it can be concluded that, urinary NGAL level cannot be used as an early diagnostic test of nephropathy in children with CHD.
\end{abstract}

Implication for health policy/practice/research/medical education:

In this case-control study, we compared the mean urinary neutrophil gelatinase-associated lipocalin (NGAL) levels in children with congenital heart disease and in healthy children. We found no significant difference between NGAL levels in these two groups. Therefore, urinary NGAL may not be considered as a good predictor of renal involvement in children with congenital heart disease.

Please cite this paper as: Momtaz EH, Tanasan A, Godini M. Evaluation of urinary NGAL level in children with congenital heart disease as a possible early indicator of nephropathy. J Nephropharmacol. 2021;10(2):e14. DOI: 10.34172/npj.2021.14.

\section{Introduction}

Renal involvement has been recognized as a complication caused by cardiovascular disease, particularly cyanotic congenital heart disease (CHD). Moreover, this type of nephropathy may present as proteinuria or renal dysfunction. Accordingly, the major problem is that when nephropathy is diagnosed in patients with $\mathrm{CHD}$, it has already reached the irreversible stages, so there is little chance to change the course of renal damage. Therefore, these patients, besides their underlying heart disease, may suffer from chronic kidney disease $(1,2)$.

In contemporary medical practice, renal impairment is routinely verified by an increase in serum creatinine. Unfortunately, due to many reasons, serum creatinine is an inaccurate index of early kidney dysfunction $(3,4)$. In addition, serum creatinine is dependent on age, gender, and muscle mass. Also, a significant increase may not be detected in serum creatinine until the occurrence of a remarkable renal dysfunction $(5,6)$.

Early recognition of renal dysfunction before presentation of clinical manifestations mainly depends on the specifications of biomarkers. Therefore, investigating new laboratory diagnostic methods that can be used at the early stages of kidney damage is likely to be very valuable. 
In this regard, one of the newest methods that has been identified for early diagnosis of renal dysfunction is measuring of urinary neutrophil gelatinase-associated lipocalin (NGAL).

NGAL is a protein from lipocalin family, which was firstly isolated from neutrophils (7-9). Accordingly, it is produced by various types of cells, such as endothelial cells, epithelial cells of gut and respiratory tract, renal tubular, and cardiac cells. NGAL is detectable at minimum levels in digestive tract, cardiac, and renal tissues (10).

Growing evidence suggests that NGAL may be upregulated in 'stressed' cells, especially in cardiomyocytes, which its correlation with heart failure is important $(11,12)$. Due to the high incidence and poor prognosis associated with worsening renal function in heart failure, previous reports have highlighted a role for NGAL in the prediction of renal dysfunction in decompensated chronic heart failure $(13,14)$.

\section{Objectives}

This study aimed to evaluate the role of urinary NGAL, as a biomarker of renal damage in children with $\mathrm{CHD}$, by comparing urinary levels of this substance between healthy children (control group) and patients with CHD.

\section{Patients and Methods}

Study design

We designed this case-control study to compare urinary NGAL levels in two groups of healthy children with no history or physical finding of heart disease as the control group and the case group including children diagnosed with CHD.

Forty-two children whose CHD was confirmed by a pediatric cardiologist, were enrolled in this study. The control group included an equal number of children in the same age range who were referred to pediatrics clinic. Children in the control group had no history of cardiac problem or renal disease including urinary tract infection. The participants were treated by no nephrotoxic drugs and had no radiocontrast study.

After obtaining the informed consent from these children's parents, urine sample was obtained from all the patients in case group as well as all children in the control group. Urinary NGAL level was measured by NGAL Rapid ELISA Kit in terms of the instructions of the manufacturer of the kit using the ELISA (enzyme-linked immunosorbent assay) reader machine. Additionally, urinary NGAL levels in these two groups were documented in data sheet along with other variables and demographic information of the participants.

\section{Ethical issues}

The research followed the tenets of the Declaration of Helsinki. The Ethics Committee of Hamadan University of Medical Sciences approved this study (Ethical code: P.16.35.10.77). Written informed consent was obtained from all the participants included before study. This study was extracted from the pediatric speciality thesis of Majid Godini at Hamadan University of Medical Sciences (Thesis \#3976).

\section{Data analysis}

Evaluation of normality of data in the two groups was done by Kolmogorov-Smirnov test and due to achieving a meaningful result $(P<0.05)$, a non-parametric test (Mann-Whitney $U$ test) was used to compare average values of Urinary NGAL in the case and control groups. Data analysis was performed using SPSS 16 software and a $P$ value less than 0.05 was considered as significant.

\section{Results}

The participants in this study were 84 patients, 42 subjects with $\mathrm{CHD}$ and 42 subjects without $\mathrm{CHD}$ and renal involvement (control group). Sex distribution in two groups was as follows: case group, 25 males (59.5\%) and $17(40.5 \%)$ females; control group, $30(71.4 \%)$ males and $12(28.6 \%)$ females( Figure 1).

The average and standard deviation of urinary NGAL in congenital heart patients was $3.84 \pm 6.9 \mathrm{ng} / \mathrm{dL}$ (the minimum 0.1 and the maximum 41.18). Additionally, the average and standard deviation of urinary NGAL in the control group was $2.01 \pm 2.04 \mathrm{ng} / \mathrm{dL}$ (the minimum 0.39 and the maximum 19.07) (Table 1).

According to the initial results obtained from Kolmogorov-Smirnov test $(P<0.001)$, which showed abnormal distribution of data in two groups, the MannWhitney $U$ test was used to compare the average level of urinary NGAL in the case and control participants. According to the results of the above table, there was no significant difference between the average urinary NGAL levels of CHD patients and the control group.

As shown, the average urinary NGAL was higher in

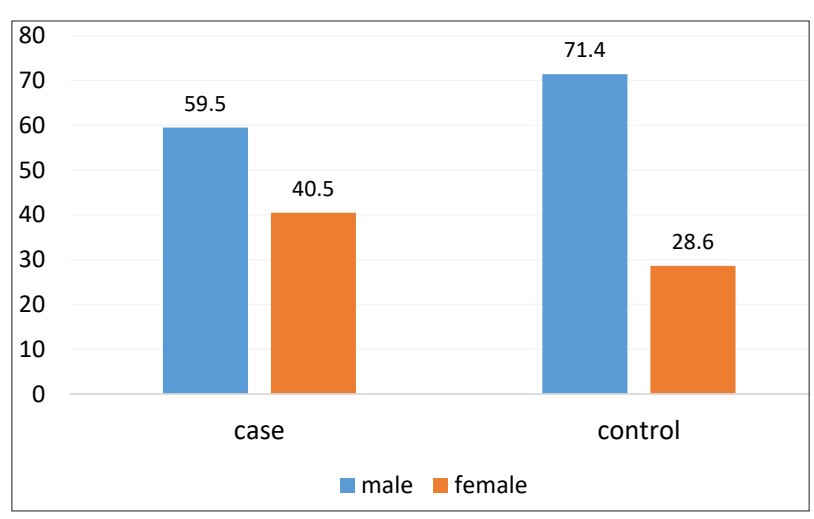

Figure 1. Frequency distribution chart for the patients with $\mathrm{CHD}$ (case) and healthy group (control) based on gender. 
Table 1. Frequency distribution of central indices and distribution of NGAL in the patients with $\mathrm{CHD}$ and the control group

\begin{tabular}{llccc}
\hline \multirow{2}{*}{ Group } & \multirow{2}{*}{ Number } & \multicolumn{2}{c}{ NGAL } & \multirow{2}{*}{$\boldsymbol{P}$ value } \\
\cline { 3 - 4 } & & Mean & SD & \\
\hline Case & 42 & 3.84 & 6.9 & \multirow{2}{*}{0.41} \\
Control & 42 & 2.01 & 3.01 & \\
\hline
\end{tabular}

Table 2. Frequency distribution table of urinary NGAL in the case and control group based on gender

\begin{tabular}{lcccc}
\hline Group & Gender & Mean & SD & P value \\
\hline \multirow{2}{*}{ Case } & Female & 3.9 & 4.4 & \multirow{2}{*}{0.92} \\
\multirow{2}{*}{ Control } & Male & 3.7 & 8.3 & \\
& Female & 3.44 & 5.25 & 0.05 \\
\hline
\end{tabular}

females in both groups compared to males. However, their differences were not statistically significant (Table 2).

\section{Discussion}

The need for a precise, quick, and reliable biomarker for the early diagnosis of renal parenchymal damage is an important issue for clinical experts and researchers in the field of nephrology. Although creatinine is currently used as a standard method, its limitations are well-known, and its serum level depends on the age, gender, and muscle mass of the patient (15). More recently, several new kidney biomarkers have been suggested for early recognizing renal damage such as cystatin-c, kidney injury molecule 1 , interleukin 8 , tissue inhibitor metalloproteinase 2 , insulin like growth factor binding protein 7, gelsolin, and NGAL (16). Currently, urinary NGAL biomarker is more widely considered due to rapid diagnosis and rapid laboratory performance. However, the reported cut off points for the diagnosis of kidney damage are different in various studies (17-19).

Elsharawy et al evaluated the association of plasma NGAL level with worsening of renal function. In this regard, they compared plasma NGAL level between 30 children with heart failure and 20 healthy children. They concluded that the higher serum level of NGAL at the time of admission in children with acute cardiac failure can be the predictor of the renal function worsening (20). The differences between our study and the study by Elsharawy et al are the number of the patients, type of NGAL measurement (urinary versus plasma), age of the patients (between 0 and 18 years old versus 48 month), and the final results( in our study, the average urinary NGAL level was higher in children with CHD compared to healthy children, but this difference was not significant, since in their study, the serum level of NGAL was significantly higher in children with acute cardiac failure compared to the control group).

Tawfeek et al showed that serum NGAL level was significantly higher in children with heart failure compared to the control group; however, there was no statistically significant association between levels of myocardial performance indices and NGAL (21). Differences between our study and the study by Tawfeek et al included number and age of the patients ( $0-18$ years old versus $0-16$ years old), as well as the type of NGAL (urinary versus plasma).

Kari et al studied the values of NGAL and cystatin C in the early detection of acute renal injury (AKI) on 40 children admitted to PICU. Accordingly, they found that both urinary NGAL and serum cystatin-C may be useful in early detection of AKI with acceptable sensitivity and specificity (22).

Recently, Greenberg et al conducted a study to test the renal injury biomarkers after cardiac surgery. They measured urine interleukin-18, kidney injury molecule-1, monocyte chemoattractant protein-1, YKL-40, and NGAL by passing five years from cardiac surgery and finally concluded that, postoperative kidney injury is not associated with urinary biomarkers five years after surgery (23).

Similarly, Holzscheiter et al in a study investigated the diagnostic values of NGAL, L-FABP, and KIM-1 in urine for kidney dysfunction. Moreover, they concluded that NGAL and L-FABP in urine are potential biomarkers in the diagnosis of renal impairment (24).

More recently, Törnblom et al studied the urinary NGAL levels in 484 adult patients with sepsis. Finally, they concluded that urinary NGAL is not a suitable biomarker to predict acute kidney injury in septic patients (25).

\section{Conclusion}

Although some studies have shown the value of urinary NGAL as a biomarker of acute kidney injury in children, there is not enough evidence on the role of this substance in early prediction of subacute or chronic kidney damage. Also, our study showed no statistically significant difference in urinary NGAL level between healthy children and those with CHD; therefore, it cannot be considered as a useful biomarker for the prediction of chronic nephropathy in this group of patients. More studies with larger populations are needed to evaluate urinary NGAL and other possible biomarkers for early detection of nephropathy to cardiac disease in children.

\section{Limitations of study}

Small population in both case and control groups, nonhomogeneity of the patients due to various types of CHDs, different time periods of the initiation of heart disease, and measurement of urinary NGAL level were the limitations of our study. Therefore, performing future studies with larger sample sizes and sub-classification of children with heart disease according to their underlying diseases and duration of involvement, is recommended. 


\section{Authors' contribution}

HEM participated in the study concept, design, critical revision, and writing the final version of manuscript. MG and AT performed data collection. All the authors read and signed the final paper.

\section{Conflicts of interest}

Authors declare that they have no conflict of interests.

\section{Ethical considerations}

Research ethics including the avoidance of double publication and plagiarism have been observed by the authors.

\section{Funding/Support}

This study was funded by deputy of research and technology of Hamadan University of medical sciences. It was extracted from thesis of Majid Godini in Hamadan University of Medical Sciences.

\section{References}

1. Hongsawong N, Khamdee P, Silvilairat S, Chartapisak W. Prevalence and associated factors of renal dysfunction and proteinuria in cyanotic congenital heart disease. Pediatr Nephrol. 2018;33:493-501. doi:10.4070/kcj.2018.0128

2. Gupte PA, Vaideeswar P, Kandalkar BM. Cyanotic nephropathy--a morphometric analysis. Congenit Heart Dis. 2014;9(4):280-285. doi: 10.1111/chd.12121.

3. Devarajan P. Neutrophil gelatinase-associated lipocalin (NGAL): a new marker of kidney disease. Scand J Clin Lab Invest Suppl. 2008;241:89-94. doi: $10.1080 / 00365510802150158$.

4. Nickolas TL, Barasch J, Devarajan P. Biomarkers in acute and chronic kidney disease. Curr Opin Nephrol Hypertens. 2008;17:127-32. doi: 10.1097/MNH.0b013e3282f4e525.

5. Srisawat N, Kellum JA. The role of biomarkers in acute kidney injury. Crit Care Clin. 2020;36:125-40. doi: 10.1016/j.ccc.2019.08.010.

6. Chen L-S, Singh RJ. Utilities of traditional and novel biomarkers in the management of acute kidney injury. Crit Rev Clin Lab Sci. 2020;57:215-26. doi: $10.1080 / 10408363.2019 .1689916$.

7. Devarajan P. NGAL in acute kidney injury: from serendipity to utility. Am J Kidney Dis. 2008;52:395-9. doi: 10.1053/j. ajkd.2008.07.008.

8. Filiopoulos V, Biblaki D, Vlassopoulos D. Neutrophil gelatinase-associated lipocalin (NGAL): a promising biomarker of contrast-induced nephropathy after computed tomography. Ren Fail. 2014;36:979-86. doi:10.3109/088602 2X.2014.900429

9. Liao B, Nian W, Xi A, Zheng M. Evaluation of a diagnostic test of serum neutrophil gelatinase-associated lipocalin (NGAL) and urine KIM-1 in Contrast-Induced Nephropathy (CIN). Med Sci Monit. 2019;25:565-70. doi: 10.12659/MSM.912569.

10. Buonafine M, Martinez-Martinez E, Jaisser F. More than a simple biomarker: the role of NGAL in cardiovascular and renal diseases. Clin Sci (Lond). 2018;132:909-23. doi:10.1042/CS20171592

11. Poniatowski B, Malyszko J, Bachorzewska-Gajewska H, Malyszko JS, Dobrzycki S. Serum neutrophil gelatinaseassociated lipocalin as a marker of renal function in patients with chronic heart failure and coronary artery disease. Kidney Blood Press Res. 2009;32:77-80 doi: $10.1159 / 000208989$.

12. Yndestad A, Landro L, Ueland T, Dahl CP, Flo TH, Vinge LE, et al. Increased systemic and myocardial expression of neutrophil gelatinase-associated lipocalin in clinical and experimental heart failure. Eur Heart J. 2009;30:1229-3. doi: 10.1093/eurheartj/ehp088.

13. Damman K, Masson S, Hillege HL, Maggioni AP, Voors AA, Opasich C, et al. Clinical outcome of renal tubular damage in chronic heart failure. Eur Heart J. 2011;32:270512. doi: 10.1093/eurheartj/ehr190.

14. Aghel A, Shrestha K, Mullens W, Borowski A, Tang WH. Serum neutrophil gelatinase-associated lipocalin (NGAL) in predicting worsening renal function in acute decompensated heart failure. J Card Fail. 2010;16:49-54. doi: $\quad$ 10.1016/j.cardfail.2009.07.003.

15. Lopez-Giacoman S, Madero M. Biomarkers in chronic kidney disease, from kidney function to kidney damage. World J Nephrol. 2015;4:57-73. doi: 10.5527/wjn.v4.i1.57.

16. Su Y, Gong Z, Wu Y, Tian Y, Liao X. Diagnostic value of urine tissue inhibitor of metalloproteinase-2 and insulinlike growth factor-binding protein 7 for acute kidney injury: a meta-analysis. PLoS One. 2017;12:e0170214. doi: 10.1371/journal.pone.0170214.

17. Lumlertgul N, Amprai M, Tachaboon S, Dinhuzen J, Peerapornratana S, Kerr SJ, Srisawat N. Urine neutrophil gelatinase-associated lipocalin (NGAL) for prediction of persistent AKI and major adverse kidney events. Sci Rep. 2020;10:8718. doi: 10.1038/s41598-020-65764-w.

18. Wettersten N, Horiuchi Y, van Veldhuisen DJ, Mueller C, Filippatos G, Nowak R, et al. Short-term prognostic implications of serum and urine neutrophil gelatinaseassociated lipocalin in acute heart failure: findings from the AKINESIS study. Eur J Heart Fail. 2020;22:251-63. doi: 10.1002/ejhf.1642.

19. Dobilienė D, Masalskienė J, Rudaitis Š, Vitkauskienė A, Pečiulytė J, Kèvalas R. Early diagnosis and prognostic value of acute kidney injury in critically Ill patients. Medicina (Kaunas). 2019;55(8):506. doi: 10.3390/medicina55080506.

20. Elsharawy S, Raslan L, Morsy S, Hassan B, Khalifa N. Plasma neutrophil gelatinase-associated lipocalin as a marker for the prediction of worsening renal function in children hospitalized for acute heart failure. Saudi J Kidney Dis Transpl. 2016;27:49-54. doi: 10.4103/1319-2442.174071.

21. Tawfeek MS, Raafat DM, Saad K, Idriss NK, Sayed S, Fouad DA, et al. Plasma levels of neutrophil gelatinase-associated lipocalin in children with heart failure. Ther Adv Cardiovasc Dis. 2016;10:30-36. doi: 10.1177/1753944715619116.

22. Kari JA, Shalaby MA, Sofyani K, Sanad AS, Ossra AF, Halabi RS, et al. Urinary neutrophil gelatinase-associated lipocalin (NGAL) and serum cystatin C measurements for early diagnosis of acute kidney injury in children admitted to PICU. World J Pediatr. 2018;14:134-42. doi: 10.1007/ 
s12519-017-0110-x.

23. Greenberg JH, Devarajan P, Thiessen-Philbrook HR, Krawczeski C, Parikh CR, Zappitelli M, et al. Kidney injury biomarkers 5 years after AKI due to pediatric cardiac surgery. Pediatr Nephrol. 2018;33:1069-77. doi: 10.1007/ s00467-018-3888-4.

24. Holzscheiter L, Beck C, Rutz S, Manuilova E, Domke I, Guder WG, et al. NGAL, L-FABP, and KIM-1 in comparison to established markers of renal dysfunction. Clin Chem Lab Med. 2014;52(4):537-546. doi: 10.1515/cclm-2013-0693.

25. Törnblom S, Nisula S, Petäjä L, Vaara S, Haapio M, Pesonen E, et al. Urine NGAL as a biomarker for septic AKI: a critical appraisal of clinical utility-data from the observational FINNAKI study. Ann Intensive Care. 2020;10:51. doi: 10.1186/s13613-020-00667-7.

Copyright (c) 2021 The Author(s); Published by Published by Society of Diabetic Nephropathy Prevention. This is an open-access article distributed under the terms of the Creative Commons Attribution License (http://creativecommons.org/licenses/by/4.0), which permits unrestricted use, distribution, and reproduction in any medium, provided the original work is properly cited. 